\title{
The relative age effect in FIFA U-17 World Cup: The role of the playing position and the continent
}

Authors' Contribution: A Study Design B Data Collection

C Statistical Analysis

D Data Interpretation

E Manuscript Preparation

F Literature Search

G Funds Collection

\author{
Ali Işın ABCDEF, Tuba Melekoğlu ABCDEF \\ Department of Coaching Education, Faculty of Sport Sciences, \\ Akdeniz University, Antalya, Turkey
}

abstract

Background: The aim of this study was to examine the relative age effect of the countries which attended the 2017 FIFA U-17 World Cup and to research the relative age effect in terms of continents and the players' position.

Material and methods: 504 male football players from 24 countries which participated in the U-17 World Cup in India in 2017 were included in the study. Football players' dates of birth were grouped into periods of three months in quarter years (Q): Q1 - January-March, Q2 - April-June, Q3 - July-September, Q4 - October-December. To study the sub-group differences of the relative age effect, meaningful chi-square $\left(\chi^{2}\right)$ values were followed by calculating the odds ratio and \%95 confidence intervals. To determine the effect size, Cramer's V was used.

Results: The relative age effect was based on quarter years' distributions. Significant differences were found among age quartiles for all teams in FIFA U-17 World Cup. However, when the variables analysed were according to the continents, the relative age effect disappeared in Africa, Asia and Oceania.

Conclusions: In the comparison of the players' continents, a relative age effect was observed in Europe, North America, and South America. When the players' positions are compared, a relative age effect was found in defenders, midfielders and forward players.

Key words: relative age effect, football, continent, World Cup, playing position.

\section{article details}

Article statistics:

Full-text PDF:

Received: December 2019; Accepted: April 2020; Published: June 2020

Copyright

Indexation:

http://www.balticsportscience.com

(c) Gdansk University of Physical Education and Sport, Poland

Celdes, Clarivate Analytics Emerging Sources Citation Index (ESCI), CNKI Scholar (China National Knowledge Infrastructure), CNPIEC, De Gruyter - IBR (International Bibliography of Reviews of Scholarly Literature in the Humanities and Social Sciences), De Gruyter - IBZ (International Bibliography of Periodical Literature in the Humanities and Social Sciences), DOAJ, EBSCO - Central \& Eastern European Academic Source, EBSCO - SPORTDiscus, EBSCO Discovery Service, Google Scholar, Index Copernicus, J-Gate, Naviga (Softweco, Primo Central (ExLibris), ProQuest - Family Health, ProQuest - Health \& Medical Complete, ProQuest - Illustrata: Health Sciences, ProQuest - Nursing \& Allied Health Source, Summon (Serials Solutions/ProQuest, TDOne (TDNet), Ulrich's Periodicals Directory/ulrichsweb, WorldCat (OCLC)

Funding: This research received no specific grant from any funding agency in the public, commercial, or not-for-profit sectors.

Conflict of interests: Corresponding author: Authors have declared that no competing interest exists.

Ali IŞIN, Department of Coaching Education, Faculty of Sport Sciences, Akdeniz University, Antalya, Turkey; email: isin_ali@ hotmail.com.

Open Access License:

This is an open access article distributed under the terms of the Creative Commons Attribution-Non-commercial 4.0 International (http://creativecommons.org/licenses/by-nc/4.0/), which permits use, distribution, and reproduction in any medium, provided the original work is properly cited, the use is non-commercial and is otherwise in compliance with the license. 


\section{INTRODUCTION}

Maturation of children continues day by day as a result of physical and mental development. Children are usually categorized into chronological age groups based on specific cut-off date so that equal opportunities are given developmentally. In terms of school, classes are arranged by grouping students who are born in the same 12-month period [1]. Unfortunately, as children are categorized into the age groups, there are continuous physical, emotional and cognitive differences between the youngest ones who are born in December and the oldest ones who are born in January [2, 3].

Similarly, in order to provide equality and the same chances of success in youth races, athletes are categorized into different groups chronologically according to their ages [2]. However, using these categories does not seem enough, as there is a 12-month difference between the youngest and the oldest athletes. In this respect, as there are important anthropometric and physiological changes during puberty, a football player who was born in January (respectively old) is going to have a 1-year advantage in comparison to a football player who was born in December (respectively young) [4]. As a result, a tendency to select the oldest football players in each category is called a relative age effect (RAE) [5].

The appearance of RAE is connected with great biological changes in chronological age groups during childhood and puberty [6]. It is widely known that the role of maturity affects aerobic power, muscle power, strength, endurance and speed in addition to the body size and fat-free mass [7]. In sports in which body size, strength and power provide an advantage, early maturity of some children in an age group during puberty is an advantage in comparison to their peers who mature later [3]. REA is strikingly obvious in activities in which performance is highly related with age and the level of maturity [8].

Helsen at al. 2000 stated that the relative age effect is affected by the difference in experience. If one is born in January and the other in December of the same calendar year, the two children of the same age group can be quite different in terms of football experience. This possible difference may make it difficult to select a less experienced player [9]. Most team sports, including football, in European countries consist of participants who are born between $1^{\text {st }}$ January and $31^{\text {st }}$ December of the same year. It is thought that these 12-months differences will provide important advantages among young athletes [5]. Unfortunately, as the talent selection of athletes is highly based on physical size, physically less developed, but skilled players are less likely to be selected compared to those born at the beginning of the selection year. Therefore, many important talents may be lost to sport [9].

RAE was studied in different sports disciplines, such as hockey [10], rugby [11], volleyball [12] and especially football [13-15]. Most studies focusing on RAE in football have shown that players who are born at the beginning of the year are more successful in this sport [16]. Therefore, prestigious clubs who are in upper leagues choose their football players considering this effect [17]. The aim of this study is to examine the relative age effect of countries that participated in 2017 FIFA U-17 World Cup and to research the relative age effect in terms of continents. Another aim of this study is to research the relative age effect according to football players' positions. 


\section{MATERIAL AND METHODS}

\section{SAMPLE}

504 male football players were included in the study from 24 countries which participated in FIFA U-17 World Cup in India in 2017. Football players were divided into four categories according to their position; goalkeeper (n:71), defender (n:153), midfielder (n:170) and forward (n:110), and six categories according to their continents; Africa (n:84), Asia (n:105), Europa (n:105), North America (n:84), Oceania (n:42) and South America (n:84).

\section{DATA COLLECTION}

Statistical data used in this study were taken from the official website of the International Federation of Football Association (FIFA), www.fifa.com. Taken from this website, players' names-surnames, birth dates, countries, continents and playing positions were included in the study. The study was conducted in accordance with the principles of the Declaration of Helsinki and approved by the Akdeniz University Clinical Research Ethics Committee (299-2020).

\section{DATA ANALYSIS}

$1^{\text {st }}$ January is the cut-off date for football players internationally, thus January was accepted as the first and December as the last month for whole statistical analyses [17]. The dates of birth were grouped into 3-month-periods as quartiles (Q): Q1 - (January-March), Q2 - (April-June), Q3 - (July-September), Q4 (October-December). Kolmogorov-Smirnov test was applied to test the normal distribution of data, and the results suggested a normal distribution. For the observed and theoretically expected differences among the distribution of birth dates, chi-square $\left(\chi^{2}\right)$ goodness-of-fit tests were applied. Since an equal birth rate is theoretically accepted in all months [18], an equal birth distribution was assumed for the analyses. In order to determine the effect size, Cramer's $V$ was used. According to Cramer [19], small effect $(V=0.06-0.17)$, medium effect $(\mathrm{V}=0.18-0.29)$ and large effect $(\mathrm{V} \geq 0.30)$ for $\mathrm{df3}$, which is the case in each comparison in our study. In order to determine Q1 vs Q4, Q1 vs Q3 and Q1 vs Q2 comparisons, odds ratios (OR) and 95\% confidence intervals were calculated. All statistical analyses were performed using SPSS 23.0 package program, and the statistical significance was accepted as $\mathrm{p}<0.05$.

\section{RESULTS}

Birth month distributions of participants are presented according to players' continents and positions (see Table 1.) In addition, $\chi^{2}$ and Cramer's V results are presented in each continent and position variables with their associated significance values. According to Table 1, there were statistically significant differences and a large effect size in Europe, North America and South America, and a medium effect size in Oceania.

According to the players' positions, statistically significant bias was detected in all positions except the goalkeeper. According to players' continents, the highest value was obtained in Europe and the lowest one in Africa. In addition, as to their positions, the highest and lowest values were noted for midfielders and goalkeepers, respectively. Odds ratio (and 95\% confidence intervals) values are shown in Table 2 in order to see in which quarters these significant differences were found. 
According to Table 2, significant differences were found among Q1-Q4, Q1-Q3 and Q1-Q2 in FIFA U-17 World Cup. For this reason, it can be figured out that countries in the tournament tended to select for the national teams those who were born in the first quarter of the year. Statistically significant differences were found between Q1 and Q4 in Europe, North America and South America. In addition, statistically significant differences were found between Q1 and Q4 in all player's positions except the goalkeeper. According to the continents, the highest odds ratio value was obtained in North America and lowest one was in Africa.

Table 1. Birth month distributions of participants according to continents and positions

\begin{tabular}{|c|c|c|c|c|c|c|c|c|}
\hline \multicolumn{9}{|c|}{ Quarter of birth ( $\%$ of player) } \\
\hline & & Q1 (\%) & Q2 (\%) & Q3 (\%) & Q4 (\%) & $x^{2}$ & $\rho$ & V \\
\hline \multirow{6}{*}{ 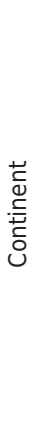 } & Africa (n:84) & $24(28.6)$ & $14(16.7)$ & $24(28.6)$ & $22(26.2)$ & 3.238 & .356 & $\begin{array}{c}0.11 \\
\text { (small) }\end{array}$ \\
\hline & Asia (n:105) & $34(32.4)$ & $29(27.6)$ & $22(21.0)$ & $20(19.0)$ & 4.752 & .191 & $\begin{array}{c}0.12 \\
\text { (small) }\end{array}$ \\
\hline & Europe (n:105) & $52(49.5)$ & $20(19.0)$ & $22(21.0)$ & $11(10.5)$ & 36.295 & .000 & $\begin{array}{c}0.34 \\
\text { (large) }\end{array}$ \\
\hline & North America (n:84) & $38(45.2)$ & $21(25.0)$ & $20(23.8)$ & $5(6.0)$ & 26.000 & .000 & $\begin{array}{c}0.32 \\
\text { (large) }\end{array}$ \\
\hline & Oceania (n:42) & $12(28.6)$ & $15(35.7)$ & $10(23.8)$ & $5(11.9)$ & 5.048 & .168 & $\begin{array}{c}0.20 \\
\text { (medium) }\end{array}$ \\
\hline & South America ( $n: 84)$ & $40(47.6)$ & $24(28.6)$ & $10(11.9)$ & $10(11.9)$ & 29.143 & .000 & $\begin{array}{c}0.34 \\
\text { (large) }\end{array}$ \\
\hline \multirow{5}{*}{ 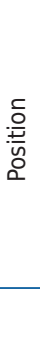 } & Goalkeeper (n:71) & $22(31.0)$ & $15(21.1)$ & $22(31.0)$ & $12(16.9)$ & 4.324 & .229 & $\begin{array}{c}0.14 \\
\text { (small) }\end{array}$ \\
\hline & Defender (n:153) & $62(40.5)$ & $40(26.1)$ & $28(18.3)$ & $23(15.0)$ & 23.654 & .000 & $\begin{array}{c}0.23 \\
\text { (medium) }\end{array}$ \\
\hline & Midfielder (n:170) & $68(40.0)$ & $48(28.2)$ & $32(18.8)$ & $22(12.9)$ & 28.494 & .000 & $\begin{array}{c}0.24 \\
\text { (medium) }\end{array}$ \\
\hline & Forward (n:110) & $48(43.6)$ & $20(18.2)$ & $26(23.6)$ & $16(14.5)$ & 22.218 & .000 & $\begin{array}{c}0.26 \\
\text { (medium) }\end{array}$ \\
\hline & Total (n:504) & $200(39.7)$ & $123(24.4)$ & $108(21.4)$ & $73(14.5)$ & 68.397 & .000 & $\begin{array}{c}0.21 \\
\text { (medium) }\end{array}$ \\
\hline
\end{tabular}

Q1: (January-March), Q2: (April-June), Q3: (July-September), Q4: (October-December)

small effect: $\mathrm{V}=0.06-0.17$, medium effect: $\mathrm{V}=0.18-0.29$, large effect: $\mathrm{V} \geq 0.30$

Table 2. Odds ratio comparisons (95\% confidence interval) between quartiles according to participants' continents and their positions

\begin{tabular}{|c|c|c|c|c|}
\hline & & \multicolumn{3}{|c|}{ Odds ratio comparisons ( $95 \%$ confidence interval) } \\
\hline & & Q1-Q4 & Q1-Q3 & Q1-Q2 \\
\hline \multirow{6}{*}{ 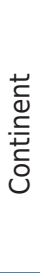 } & Africa (n:84) & $1.09(0.47-2.52)$ & $1.00(0.44-2.29)$ & $1.71(0.70-4.19)$ \\
\hline & Asia (n:105) & $1.70(0.78-3.68)$ & $1.55(0.72-3.31)$ & $1.17(0.56-2.44)$ \\
\hline & Europe (n:105) & $4.73(2.03-11.02) *$ & $2.36(1.13-4.93)^{*}$ & $2.60(1.23-5.49) *$ \\
\hline & North America ( $\mathrm{n}: 84)$ & 7.60 (2.50-23.09)* & $1.90(0.84-4.28)$ & $1.81(0.81-4.05)$ \\
\hline & Oceania (n:42) & $2.40(0.62-9.25)$ & $1.20(0.36-3.98)$ & $0.80(0.25-2.51)$ \\
\hline & South America (n:84) & $4.00(1.59-10.04) *$ & $4.00(1.59-10.04) *$ & $1.67(0.76-3.67)$ \\
\hline \multirow{5}{*}{$\frac{ㅇ}{\frac{0}{n}}$} & Goalkeeper (n:71) & $1.83(0.70-4.80)$ & $1.00(0.41-2.42)$ & $1.47(0.58-3.71)$ \\
\hline & Defender (n:153) & $2.70(1.40-5.19) *$ & $2.21(1.18-4.17)^{*}$ & $1.55(0.85-2.82)$ \\
\hline & Midfielder (n:170) & $3.09(1.63-5.87)^{*}$ & $2.13(1.17-3.86)^{*}$ & $1.42(0.81-2.49)$ \\
\hline & Forward (n:110) & $3.00(1.38-6.51)^{*}$ & $1.85(0.91-3.76)$ & $2.40(1.14-5.04)^{*}$ \\
\hline & Total (n:504) & $2.74(1.90-3.94)^{*}$ & $1.85(1.32-2.60)^{*}$ & $1.63(1.16-2.27)^{*}$ \\
\hline
\end{tabular}

Q1: (January-March), Q2: (April-June), Q3: (July-September), Q4: (October-December) 


\section{DISCUSSION}

The aim of this study was to examine the relative age effect of the countries which participated in the 2017 FIFA U-17 World Cup and to research the relative age effect in terms of continents and players' position.

Some physical differences can be observed between football players born in the first quarter and those born in the fourth quarter. It is considered that those born in the early months of the year are not equal to those born in the later months especially in lower age categories $[4,5,15]$.

Most of the studies on RAE focus on football. Earlier studies about football show that relative age of the individuals in the related group affects both the possibility of participation and the possibility of success [14]. According to our results, RAE was determined in the FIFA U-17 World Cup $\left(\chi^{2}: 68.397, p<0,001\right)$. Similarly, Helsen et al. [14] reported that an exact RAE was found in the UEFA U-16 tournaments as well as in all national youth selections in the U-15, U-16, U-17 and U-18 categories. Brustio et al. [20] found a very large relative age effect in U-15, U-16 and U-17 Italian football players. Williams [18] reported that a relative age effect was seen in the FIFA U-17 World Cup between 1997-2007. In other words, it is more likely that those born in the first half of the year were selected more than those born in the second half of the year. González-Víllora et al. [17] reported that although there is no RAE in professional football players, there is a remarkable effect in lower age categories. This effect is the highest in U-17.

In our research, we found RAE in European, North American and South American teams $\left(\chi^{2}: 36.295,26.000,29.143 ; p<0,001\right.$ respectively). Also, those born in the first half of the year were more numerous than those born in the second half of the year in Asia and Oceania, and the highest odds ratio value was obtained in North America and lowest was in Africa. It can be thought that football players who are born in the first quarter of the year have a 7-times more chance to be selected than those born in the fourth quarter in North America. Moreover, as to players' positions, the highest and the lowest odds ratio values were noted for midfielders and goalkeepers. However, it was found that those born in the first half of year were fewer than those born in the second half of the year in Africa. Therefore, although no statistically significant differences were found in Africa, it seems possible to talk about an adverse effect in Africa. In the FIFA U-17 World Cup between 1997-2007, although there was a relative age effect in all continents except in Africa, it was reported that there was an adverse effect in Africa. It is shown as a result of this that football players in Africa were born more in December (nearly $14 \%)$. Because such an adverse effect was not mentioned in Africa before, the reason behind this is not clear. However, it seems reasonable that people have not given the real birth dates as there was such a high percentage of football players who were born in one single month [18].

In Cameroon, it is seen that only $33 \%$ of all the births have been approved by a birth certificate since documents were recorded by the father [21]. Also, only half of all the births are recorded for children under 1 year of age. Therefore, they seem to have made mistakes in reporting the real birth dates [18]. Dvorak et al. [22] claimed that these mistakes could be revealed through differences between the reported birth year and the skeletal age. 
According to our results, relative age effect was discovered in defenders, midfielders and forward players $\left(\chi^{2}: 23.654,28.494,22.218 ; p<0,001\right.$ respectively). As goalkeepers and defenders are taller than midfielders [23, 24 ], we tend to think that there is more RAE in goalkeepers and defenders. Salinero et al. [25] reported that midfielders are observed to have RAE most widely. However, although this effect was not seen in midfielders of the English Premier League, it was discovered in goalkeepers, defenders and forward players. In football in which high balls are obviously important, selecting defenders and forward players from tall players is considered to play a role in this effect [25].

Middle-class or upper-class teams tend to select football players born in the early months of the year, and these teams are committed to RAE [26]. The reason for this is that those born at the beginning of the year have physical, psychological and physiological advantages in comparison to those born at the end of the year [2]. Furthermore, maturation advantages may provide greater self-confidence in football players $[27,28]$. In this respect, maturity is considered to be a factor which mostly affects the selection process of the football player [26].

There are several limitations in our study. Because the data were taken from the official website of FIFA, we could not reach the height and weight variables of the football players. There is a lack of results concerning the relationship between body size and RAE, so the variables only provide a partial explanation of RAE. Furthermore, it would be valuable to analyse the players in five positions, such as central defender, full-back, wide midfielder, forward and goalkeeper. Hence, the data in the official website of FIFA serves the data of only three in-field positions.

\section{CONCLUSIONS}

In conclusion, it is considered that RAE is followed while selecting football players for U-17 national teams, and there is a strong relative age effect in most continents. Physical maturity and selection processes may explain the RAE. This study has provided evidence of a strong relative age effect in elite football players participating in the 2017 FIFA U-17 World Cup.

As a practical application, in order to eliminate RAE in football, new age classifications are required. In the literature, most of the studies suggest conducting competitions within 6-month age ranges for youth sports. However, it seems that dividing the players into two group by age is impractical. As a practical and effective precaution to avoid the significant loss of potential youth football players, the competitions may be conducted between teams that have a relative percentage of their players coming from each of the age quartiles.

\section{REFERENCES}

[1] Barnsley RH, Thompson A, Legault P. Family planning: Football style. The relative age effect in football. Int Rev Sociol Sport. 1992;27(1):77-87. https://doi.org/10.1177/101269029202700105

[2] Musch J, Grondin S. Unequal competition as an impediment to personal development: A review of the relative age effect in sport. Dev Rev. 2001;21(2):147-67. https://doi.org/10.1006/drev.2000.0516

[3] Malina RM. Physical growth and biological maturation of young athletes. Exerc Sport Sci Rev. 1994;22(1):280-4. https://doi.org/10.1249/00003677-199401000-00012

[4] Arrieta H, Torres-Unda J, Gil SM, Irazusta J. Relative age effect and performance in the U16, U18 and U20 European Basketball Championships. J Sports Sci. 2016;34(16):1530-4. https://doi.org/10.1080/ 02640414.2015.1122204 
[5] Gil SM, Badiola A, Bidaurrazaga-Letona I, et al. Relationship between the relative age effect and anthropometry, maturity and performance in young soccer players. J Sports Sci. 2014;32(5):479-86. https://doi.org/10.1080/02640414.2013.832355

[6] Baxter-Jones AD. Growth and development of young athletes. Sports Med. 1995;20(2):59-64. https:// doi.org/10.2165/00007256-199520020-00001

[7] Malina RM, Bouchard C, Bar-Or O. Growth, maturation, and physical activity: Human Kinetics; 2004. https://doi.org/10.5040/9781492596837

[8] Thompson AH, Barnsley RH, Battle J. The relative age effect and the development of self-esteem. Educ Res. 2004;46(3):313-20. https://doi.org/10.1080/0013188042000277368

[9] Helsen WF, Hodges NJ, Winckel JV, Starkes JL. The roles of talent, physical precocity and practice in the development of soccer expertise. J Sports Sci. 2000;18(9):727-36. https://doi. org/10.1080/02640410050120104

[10] Nolan JE, Howell G. Hockey success and birth date: The relative age effect revisited. Int Rev Sociol Sport. 2010;45(4):507-12. https://doi.org/10.1177/1012690210371560

[11] Till K, Cobley S, Wattie N, O'hara J, Cooke C, Chapman C. The prevalence, influential factors and mechanisms of relative age effects in UK Rugby League. Scand J Med Sci Sports. 2010;20(2):320-9. https://doi.org/10.1111/j.1600-0838.2009.00884.x

[12] Okazaki FH, Keller B, Fontana FE, Gallagher JD. The relative age effect among female Brazilian youth volleyball players. Res Q Exerc Sport. 2011;82(1):135-9. https://doi.org/10.1080/02701367. 2011.10599730

[13] Vincent J, Glamser FD. Gender differences in the relative age effect among US Olympic Development Program youth soccer players. J Sports Sci. 2006;24(4):405-13. https://doi. org/10.1080/02640410500244655

[14] Helsen WF, Van Winckel J, Williams AM. The relative age effect in youth soccer across Europe. J Sport Sci. 2005;23(6):629-36. https://doi.org/10.1080/02640410400021310

[15] Szwarc A, Dolanski B, Rompa P, Sitek M. Relative age effect in Polish National Football teams. Baltic Journal of Health and Physical Activity. 2019;11(3):19-26. https://doi.org/10.29359/BJHPA.11.3.03

[16] Augste C, Lames M. The relative age effect and success in German elite U-17 soccer teams. J Sports Sci. 2011;29(9):983-7. https://doi.org/10.1080/02640414.2011.574719

[17] González-Víllora S, Pastor-Vicedo JC, Cordente D. Relative age effect in UEFA championship soccer players. J Hum Kinet. 2015;47(1):237-48. https://doi.org/10.1515/hukin-2015-0079

[18] Williams J. Relative age effect in youth soccer: analysis of the FIFA U17 World Cup competition. Scand J Med Sci Sports. 2010;20(3):502-8. https://doi.org/10.1111/j.1600-0838.2009.00961.x

[19] Cramér H. Mathematical methods of statistics (PMS-9): Princeton University Press; 2016.

[20] Brustio PR, Lupo C, Ungureanu AN, Frati R, Rainoldi A, Boccia GJPo. The relative age effect is larger in Italian soccer top-level youth categories and smaller in Serie A. PloS One. 2018;13(4):1-12. https:// doi.org/10.1371/journal.pone.0196253

[21] Ndong I, Gloyd S, Gale J. An evaluation of vital registers as sources of data for infant mortality rates in Cameroon. Int J Epidemiol. 1994;23(3):536-9. https://doi.org/10.1093/ije/23.3.536

[22] Dvorak J, Georges J, Junge A, Hodler J. Application of MRI of the wrist for age determination in international U-17 soccer competitions. Br J Sports Med. 2007;41(8):497-500. https://doi.org/10.1136/ bjsm.2006.033431

[23] Gil SM, Gil J, Ruiz F, Irazusta A, Irazusta J. Physiological and anthropometric characteristics of young soccer players according to their playing position: relevance for the selection process. J Strength Cond Res. 2007;21(2):438-45. https://doi.org/10.1519/00124278-200705000-00026

[24] Hencken C, White C. Anthropometric assessment of Premiership soccer players in relation to playing position. Eur J Sport Sci. 2006;6(4):205-11. https://doi.org/10.1080/17461390601012553

[25] Salinero JJ, Pérez B, Burillo P, Lesma ML. Relative age effect in European professional football. Analysis by position. J Hum Sport and Exerc. 2013;8(4). https://doi.org/10.4100/jhse.2013.84.07

[26] Práxedes A, Moreno A, García-González L, Pizarro D, Del Villar F. The Relative Age Effect on soccer players in formative stages with different sport expertise levels. J Hum Kinet. 2017;60(1):167-73. https://doi.org/10.1515/hukin-2017-0100

[27] Pellegrini AD. Kindergarten children's social-cognitive status as a predictor of first-grade success. Early Childhood Research Quarterly. 1992;7(4):565-77. https://doi.org/10.1016/0885-2006(92)90099-K

[28] van den Honert R. Evidence of the relative age effect in football in Australia. J Sport Sci. 2012;30(13):1365-74. https://doi.org/10.1080/02640414.2012.707329 